\title{
A Survey of Resistance to Tomato bushy stunt virus in the Genus Nicotiana Reveals That the Hypersensitive Response Is Triggered by One of Three Different Viral Proteins
}

\author{
Carlos A. Angel and James E. Schoelz \\ Division of Plant Sciences, University of Missouri, Columbia 65211, U.S.A. \\ Submitted 19 June 2012. Accepted 22 September 2012.
}

In this study, we screened 22 Nicotiana spp. for resistance to the tombusviruses Tomato bushy stunt virus (TBSV), $\mathrm{Cu}$ cumber necrosis virus, and Cymbidium ringspot virus. Eighteen species were resistant, and resistance was manifested in at least two different categories. In all, 13 species responded with a hypersensitive response (HR)-type resistance, whereas another five were resistant but either had no visible response or responded with chlorotic lesions rather than necrotic lesions. Three different TBSV proteins were found to trigger $\mathrm{HR}$ in Nicotiana spp. in an agroinfiltration assay. The most common avirulence (avr) determinant was the TBSV coat protein P41, a protein that had not been previously recognized as an avr determinant. A mutational analysis confirmed that the coat protein rather than the viral RNA sequence was responsible for triggering $H R$, and it triggered HR in six species in the Alatae section. The TBSV P22 movement protein triggered HR in two species in section Undulatae (Nicotiana glutinosa and N. edwardsonii) and one species in section Alatae ( $N$. forgetiana). The TBSV P19 RNA silencing suppressor protein triggered HR in sections Sylvestres (N. sylvestris), Nicotiana (N. tabacum), and Alatae ( $N$. bonariensis). In general, Nicotiana spp. were capable of recognizing only one tombusvirus avirulence determinant, with the exceptions of $N$. bonariensis and $N$. forgetiana, which were each able to recognize $P 41$, as well as P19 and P22, respectively. Agroinfiltration failed to detect the TBSV avr determinants responsible for triggering HR in $N$. arentsii, $N$. undulata, and $N$. rustica. This study illustrates the breadth and variety of resistance responses to tombusviruses that exists in the Nicotiana genus.

One of the most common strategies that plants have used for defense against pathogen infections involves a class of single, dominant resistance $(R)$ genes broadly defined as nucleotidebinding site leucine-rich repeat (NBS-LRR) genes. In many instances, the proteins encoded by NBS-LRR genes have the capacity to recognize a specific feature of a pathogen protein, termed an avirulence (avr) protein, to trigger a hypersensitive

Corresponding author: J. E. Schoelz, Telephone: +1.573 .882 .1185 ; Fax: +1.573.882.0588; E-mail: schoelzj@missouri.edu

* The $\boldsymbol{e}$-Xtra logo stands for "electronic extra" and indicates nine supplementary figures and one supplementary table are published online. Also, Figure 4 appears in color online.

(C) 2013 The American Phytopathological Society response (HR) in the plant. In the case of plant viruses, the HR is manifested as a necrotic lesion that is initiated at the point of infection. Depending on the virus-host combination, the necrotic lesion may appear as early as 1 day postinoculation (dpi) or may appear as late as 6 to $10 \mathrm{dpi}$. Plant genomesequencing projects have revealed that plants contain a large number of $R$ genes; for example, Arabidopsis thaliana ecotype Col- 0 contains 149 NBS-LRR genes (Meyers et al. 2003). Presumably, each of these $R$ gene products would recognize a specific pathogen and, collectively, they would protect plants from invasion by an array of pathogens. However, in any given host, even in Arabidopsis, the pathogen targets of most $R$ genes remain unidentified. Because a functional $\mathrm{R}$ protein can only be revealed in conjunction with its avr counterpart, one way to initially characterize an $R$ gene is to identify its avr target.

Nicotiana is a valuable genus for cataloging virus-host interactions. The Nicotiana genus consists of approximately 76 species grouped into 13 taxonomic sections (Clarkson et al. 2004; Knapp et al. 2004). Approximately $75 \%$ of Nicotiana spp. distributed between 12 sections are found in South and North America; the other $25 \%$ of Nicotiana spp., which comprise the Suaveolentes section, occur in Australia, and a single species has been found in Africa (Clarkson et al. 2004). Nicotiana benthamiana and $N$. tabacum have frequently been used as model hosts in the study of plant virology (Goodin et al. 2008; Lewis and Nicholson 2007) but many other Nicotiana spp. have also been very useful. Historically, $N$. glutinosa has played a central role in the characterization of virus resistance, because the $N$ gene in $N$. glutinosa, a gene that specifies resistance to Tobacco mosaic virus (TMV), was one of the first virus $R$ genes to be discovered (Holmes 1938, 1946) and one of the first $R$ genes to be cloned (Whitham et al. 1994). N. glutinosa exhibits resistance to many viruses in addition to TMV and, through interspecific crosses with virus-susceptible hosts such as $N$. clevelandii, it is possible to genetically characterize the inheritance of virus resistance in N. glutinosa (Schoelz et al. 2006).

Nicotiana spp. have also proven to be valuable for the identification of viral avr determinants. The first viral proteins confirmed to be avr determinants were the Cauliflower mosaic virus (CaMV) P6 protein, which triggered HR in N. edwardsonii and $N$. glutinosa (Schoelz et al. 1986), and the TMV coat protein, which triggered HR in N. sylvestris (Knorr and Dawson 1988). Avr determinants were initially identified through the use of gene swaps between infectious virus clones. However, transient expression assays have since been developed in which a putative viral $a v r$ gene can be delivered and expressed into cells by Agrobacterium tumefaciens (i.e., agroinfiltration). 
Species such as $N$. benthamiana are especially receptive to agroinfiltration (Goodin et al. 2008) but other Nicotiana spp. have also proven amenable to the technique (Angel et al. 2011; Erickson et al. 1999). In addition, in several instances, agroinfiltration has recapitulated the results obtained with chimeric viruses, demonstrating that agroinfiltration is a valid method for identification of viral avr genes. For example, the $183-\mathrm{kDa}$ replicase of TMV was shown to trigger HR mediated by the $N$ gene (Padgett and Beachy 1993) through the use of infectious clones, and the helicase domain (P50) was subsequently shown to elicit HR upon agroinfiltration (Erickson et al. 1999).

Two different tombusvirus proteins have been shown to trigger HR in Nicotiana spp. (Angel et al. 2011; Scholthof et al. 1995a). Tombusviruses have a genome composed of singlestranded positive-sense RNA approximately 4,700 nucleotides in length that is encapsidated into isometric virions 30 to $35 \mathrm{~nm}$ in diameter. Tomato bushy stunt virus (TBSV), the type member of tombusviruses, has a genome organized into six open reading frames (ORF) (Fig. 1) (Hearne et al. 1990; Yamamura and Scholthof 2005). Reading from the $5^{\prime}$ end of the genomic RNA, the first two ORF are both necessary for replication and are translated to produce a $33-\mathrm{kDa}$ protein $(\mathrm{P} 33)$ and a $92-\mathrm{kDa}$ protein (P92) (Nagy and Pogany 2008; Scholthof et al. 1995c; White and Nagy 2004). The P92 protein is a read-through product of $\mathrm{P} 33$ and contains the characteristic motifs of a viral RNA dependent RNA polymerase. The third ORF from the $5^{\prime}$ end of the genomic RNA encodes the $41-\mathrm{kDa}$ capsid or coat protein (P41), which is also required for long-distance transport (Desvoyes and Scholthof 2002; Qu and Morris 2002; Scholthof et al. 1993). The fourth and fifth ORF are nested, translated from a second, single-subgenomic RNA, and encode two proteins, P22 and P19, respectively (Hearne et al. 1990;

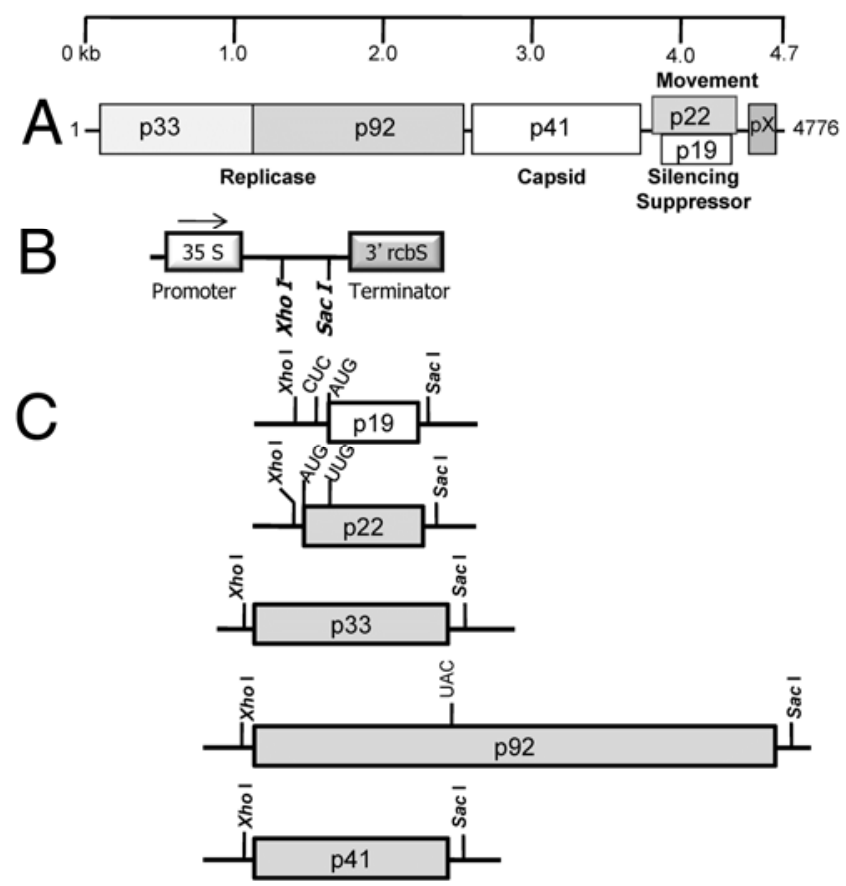

Fig. 1. Organization of the tombusvirus genome and T-DNA constructs used for transient expression of Tombusvirus genes in Agrobacterium tumefaciens. A, Tombusvirus genome structure. B, Agrobacterium binary vector pKYLX7. Tomato bushy stunt virus (TBSV) genes are inserted between the XhoI and SacI sites for expression in plants. C, Constructs for expression of individual tombusvirus genes $p 19 / p 20, p 21 / p 22, p 41, p 33$, and $p 92$, inserted into pKYLX7. The AUG indicates the start codons for the nested TBSV genes $p 19$ and $p 22$, whereas CUC and UUG indicate the mutations of those start codons. The UAC codon illustrates the mutation of the stop codon between $p 33$ and $p 92$ to allow for expression of $p 92$.
Scholthof et al. 1995b). The P19 and P22 proteins have been shown to be involved in cell-to-cell and long-distance movement, host range determination, and symptom development. The P19 protein is also known to function as a strong suppressor of post-transcriptional gene silencing (Scholthof 2006; Voinnet et al. 1999). A sixth ORF at the $3^{\prime}$ distal end of the TBSV genomic RNA encodes a small protein designated $\mathrm{pX}$, which is not essential for replication but is required for hostdependent virus accumulation (Scholthof and Jackson 1997).

In the present study, 22 Nicotiana spp. native primarily to the Americas were surveyed for their response to three different tombusviruses. We found that 18 species were resistant to the tombusviruses TBSV, Cucumber necrosis virus (CNV), and Cymbidium ringspot virus (CymRSV), and 13 of the resistant species responded with an HR. Although previous work had shown that the TBSV P22 and P19 proteins functioned as avirulence determinants in several Nicotiana spp. (Angel et al. 2011; Scholthof et al. 1995a), neither P22 nor P19 triggered HR in seven of the Nicotiana spp. in this study, indicating that other TBSV proteins must function as avr determinants. We used agroinfiltration to evaluate the potential of TBSV P33, P92, and P41 proteins to elicit HR in Nicotiana spp., and found that P41 triggered HR in the majority of species that compose the section Alatae. This study illustrates the broad spectrum of resistance that exists in the genus Nicotiana to tombusviruses. Furthermore, although several Nicotiana spp. respond with HR to tombusviruses, the $R$ genes in those species have evolved to target at least three different tombusvirus proteins.

\section{RESULTS}

\section{Survey of Nicotiana spp. for resistance to tombusvirus virion inoculations.}

To survey the genus Nicotiana for susceptibility to tombusviruses, we initially chose 17 Nicotiana spp. that were representative of the diversity that occurs in the Americas (Table 1). We also included $N$. benthamiana, a species originally found in Australia, because it provided a benchmark for virus susceptibility. Nicotiana spp. were inoculated with sap extracts from plants infected with TBSV, CNV, or CymRSV. All 18 species were tested at the same time to take into account environmental effects and were tested at least three times. In all, 10 of the 18 species responded to all three viruses with HR-type resistance, because necrotic lesions formed on the inoculated leaves at 2 to 4 dpi and no symptoms developed on upper, noninoculated leaves (Table 1). Supplementary Figures S1 through S6 illustrate the diversity in necrotic lesion response observed in the 10 species that responded with $\mathrm{HR}$ to TBSV, CNV, and CymRSV. Although each of these species developed an HR, there was considerable variation in the appearance and frequency of lesions, from the large, nearly confluent necrosis in $N$. edwardsonii to numerous pinpoint lesions in $N$. longiflora. The 10 Nicotiana spp. included some that had been shown previously to respond to tombusviruses with HR: Nicotiana spp. such as $N$. edwardsonii, N. glutinosa, N. sylvestris, and N. tabacum (Angel et al. 2011; Scholthof et al. 1995a). In all cases, enzyme-linked immunosorbent assays (ELISA) conducted between 21 and 28 dpi confirmed that these Nicotiana spp. were truly resistant to infection, because TBSV, CNV and CymRSV were not detected in upper, noninoculated leaves (data not shown).

Five Nicotiana spp. were resistant but their response to tombusvirus infection did not fit the classic description for an HR (i.e., resistance associated with rapid programmed cell death in inoculated leaves). Three species ( $N$. tomentosiformis, $N$. glauca, and $N$. otophora) responded to each of the three tombusviruses with chlorotic lesions at 3 to 5 dpi (Table 1) (Angel et al. 2011) but no symptoms developed in upper, noninocu- 
lated leaves. Another species, N. wigandioides, did not show any type of local reaction. ELISA specific to each of TBSV, $\mathrm{CNV}$, and CymRSV failed to detect any virions in upper, noninoculated leaves; therefore, we considered these four Nicotiana spp. resistant to tombusvirus infection. The fifth species, $N$. repanda, responded with a mixture of necrotic and chlorotic lesions within 3 to 5 dpi but it also could be categorized as resistant to CymRSV and CNV and partially resistant to TBSV. In the case of TBSV, upper, noninoculated $N$. repanda leaves remained symptomless but an ELISA assay for these tissues indicated a weak, positive reaction for TBSV (data not shown).

$N$. clevelandii, N. benthamiana, and $N$. quadrivalvis (syn. $N$. bigelovii) were all clearly susceptible. Each Nicotiana sp. responded to each of the three tombusviruses with severe systemic chlorosis and necrosis, with death of the plants 2 to 3 weeks after inoculation (Table 1). ELISA assays conducted on upper, noninoculated leaves confirmed the systemic movement of tombusviruses in these hosts (data not shown). This study showed that, under a single set of environmental conditions, several Nicotiana spp. in at least five sections of the Nicotiana genus responded to tombusviruses with HR.

\section{Response of Nicotiana spp. to agroinfiltration of tombusvirus P22 and P19 proteins.}

Previous studies had shown that the tombusvirus P22 protein triggers HR in N. glutinosa and $N$. edwardsonii, whereas the P19 protein triggers HR in N. tabacum and N. sylvestris (Angel et al. 2011; Scholthof et al. 1995a). To determine whether either of these proteins elicit HR in any of the Nicotiana spp. that responded to virion inoculation with HR, all 18 Nicotiana spp. were agroinfiltrated with both and infiltrated tissues were scored for the presence of HR over a period of 12 days. Because the $p 19$ gene is nested within $p 22$, each of the constructs was designed to express only $\mathrm{P} 19$ or $\mathrm{P} 22$ protein, as described previously (Angel et al. 2011).

The tombusvirus P22 (and CNV P21) proteins triggered HR in only N. glutinosa and N. edwardsonii (Table 1), the two species identified in previous studies (Angel et al. 2011; Scholthof et al. 1995a). The tombusvirus P19 (and CNV P20) proteins elicited HR in N. sylvestris, whereas the TBSV and CymRSV
P19 proteins elicited HR in N. tabacum; these species had been shown previously to respond to these tombusvirus proteins with HR (Angel et al. 2011; Scholthof et al. 1995a). The inability of CNV P20 to elicit HR in N. tabacum had been noted by Angel and associates (2011). They noted that the silencing suppressor function of CNV P20 was comparable with TBSV P19 at 8 days after infiltration (dai), an indication that the protein was expressed. They suggested that the inability of CNV P20 to elicit HR in N. tabacum in an agroinfiltration assay might be due to inherent differences between CNV P20 and either TBSV P19 or CymRSV P19. These differences might occur at the primary sequence level or in the secondary structure. The only species that responded with HR that had not been identified in a previous study was $N$. bonariensis, which responded to agroinfiltration of TBSV P19 with HR (Table 1). Interestingly, neither the CymRSV P19 nor the CNV P20 protein triggered HR in $N$. bonariensis.

These results underscored the correlation of HR elicitation during virus infections with HR induced through agroinfiltration of a specific tombusvirus protein, and indicated that a tombusvirus gene was likely responsible for HR elicitation in the context of a virus infection. However, our results also indicated that neither P22 nor P19 were responsible for triggering HR in five of 10 Nicotiana spp. that developed HR-type lesions after virion inoculations. Consequently, we hypothesized that other tombusvirus proteins, such as P33, P92, or P41, might be responsible for eliciting HR in these five Nicotiana spp.

\section{The P41 protein of TBSV triggers HR in selected Nicotiana spp.}

To determine whether tombusvirus proteins other than P22 and P19 could elicit HR in Nicotiana spp., we inserted the TBSV coat protein gene $p 41$ and the TBSV replicase genes p33 and p92 into the Agrobacterium binary vector pKYLX7 for expression in plants (Fig. 1). Each construct was agroinfiltrated into the 10 Nicotiana spp. that responded to virion inoculations with HR. We found that neither P33 nor P92 elicited HR in any Nicotiana spp. (Fig. 2A). By contrast, the TBSV P41 protein elicited HR in $N$. langsdorffii, $N$. longiflora, and $N$. bonariensis within 2 to 7 dai (Fig. $2 \mathrm{~A}$ to C); the fastest

Table 1. Response of 18 Nicotiana spp. to inoculation of tombusvirus virions and agroinfiltration of tombusvirus $p 19$ and $p 22$ genes

\begin{tabular}{|c|c|c|c|c|c|}
\hline \multirow[b]{2}{*}{ Nicotiana spp. } & \multirow[b]{2}{*}{ Section } & \multirow[b]{2}{*}{ Virion inoculation $^{b}$} & \multicolumn{3}{|c|}{ HR induced by agroinfiltration ${ }^{a}$} \\
\hline & & & TBSV & CymRSV & CNV \\
\hline Nicotiana quadrivalvis & Polydicliae & Susceptible & $\mathrm{nr}$ & $\mathrm{nr}$ & $\mathrm{nr}$ \\
\hline N. clevelandii & Polydicliae & Susceptible & $\mathrm{nr}$ & $\mathrm{nr}$ & $\mathrm{nr}$ \\
\hline N. edwardsonii & Undulatae/Polydicliae & HR & $p 22$ & $p 22$ & $p 21$ \\
\hline N. glutinosa & Undulatae & HR & $p 22$ & $p 22$ & $p 21$ \\
\hline N. arentsii & Undulatae & HR & $\mathrm{nr}$ & $\mathrm{nr}$ & $\mathrm{nr}$ \\
\hline N. wigandioides & Undulatae & $\mathrm{nr}$ & $\mathrm{nr}$ & $\mathrm{nr}$ & $\mathrm{nr}$ \\
\hline N. undulata & Undulatae & HR & $\mathrm{nr}$ & $\mathrm{nr}$ & $\mathrm{nr}$ \\
\hline N. tabacum & Nicotiana & HR & $p 19$ & p19 & $\mathrm{nr}$ \\
\hline N. langsdorffii & Alatae & HR & $\mathrm{nr}$ & $\mathrm{nr}$ & $\mathrm{nr}$ \\
\hline N. longiflora & Alatae & HR & $\mathrm{nr}$ & $\mathrm{nr}$ & $\mathrm{nr}$ \\
\hline$N$. bonariensis & Alatae & HR & $p 19$ & $\mathrm{nr}$ & $\mathrm{nr}$ \\
\hline N. repanda & Repandae & Mixed LL & $\mathrm{nr}$ & $\mathrm{nr}$ & $\mathrm{nr}$ \\
\hline N. glauca & Noctiflorae & Chlorotic LL & $\mathrm{nr}$ & $\mathrm{nr}$ & $\mathrm{nr}$ \\
\hline N. rustica & Rusticae & $\mathrm{HR}$ & $\mathrm{nr}$ & $\mathrm{nr}$ & $\mathrm{nr}$ \\
\hline N. sylvestris & Sylvestres & HR & p19 & p19 & p20 \\
\hline N. otophora & Tomentosae & Chlorotic LL & $\mathrm{nr}$ & $\mathrm{nr}$ & $\mathrm{nr}$ \\
\hline N. tomentosiformis & Tomentosae & Chlorotic LL & $\mathrm{nr}$ & $\mathrm{nr}$ & $\mathrm{nr}$ \\
\hline N. benthamiana & Suaveolentes & Susceptible & $\mathrm{nr}$ & $\mathrm{nr}$ & $\mathrm{nr}$ \\
\hline
\end{tabular}


HR occurred with $N$. langsdorffii at 2 dai, whereas the slowest was observed with $N$. longiflora at 7 to 9 dai. This variation in timing is interesting because all three species responded to virion inoculations with HR after 2 to 4 dpi. The test with $N$. longiflora also illustrated that TBSV P22 and P19 were unable to elicit HR under conditions that did lead to HR elicitation by P41 (Fig. 2A). The TBSV P41 protein did not elicit HR in $N$. tabacum, N. sylvestris, N. edwardsonii, or N. glutinosa, the Nicotiana spp. previously shown to respond with HR tombusvirus proteins P22 and P19 (data not shown). Furthermore, TBSV P41 did not elicit HR in N. rustica, N. undulata, and N. arentsii (Fig. 2D to F), three Nicotiana spp. that respond to TBSV virion inoculation with HR. Consequently, the avr determinant for these three species remains undetermined.

Szittya and Burgyán (2001) earlier reported that the coat protein coding sequence of CymRSV elicited an HR in Datura stramonium; their evidence suggested that the viral nucleic acid rather than the coat protein was the trigger for HR. Consequently, it was important to determine whether the TBSV coat protein or its nucleic acid sequence was responsible for the elicitation of HR in Nicotiana spp. An inspection of the TBSV p4l nucleotide sequence reveals eight start codons, three of which are located within the first 12 codons (Fig. 3; Supplementary Figure S7). To inactivate the first three start codons in the TBSV p4l coding sequence, we designed polymerase chain reaction (PCR) primers that converted codons 6 and 11 into stop codons, and the next start codon downstream was changed from ATG to TTC (Fig. 3A). In this mutated $p 41$ construct $(\mathrm{p} 41 \mathrm{KO})$, ribosomes would initiate translation at the correct $p 41$ start codon and almost immediately encounter two stop codons; in addition, the possibility of reinitiation at the third start codon was eliminated through its mutation.
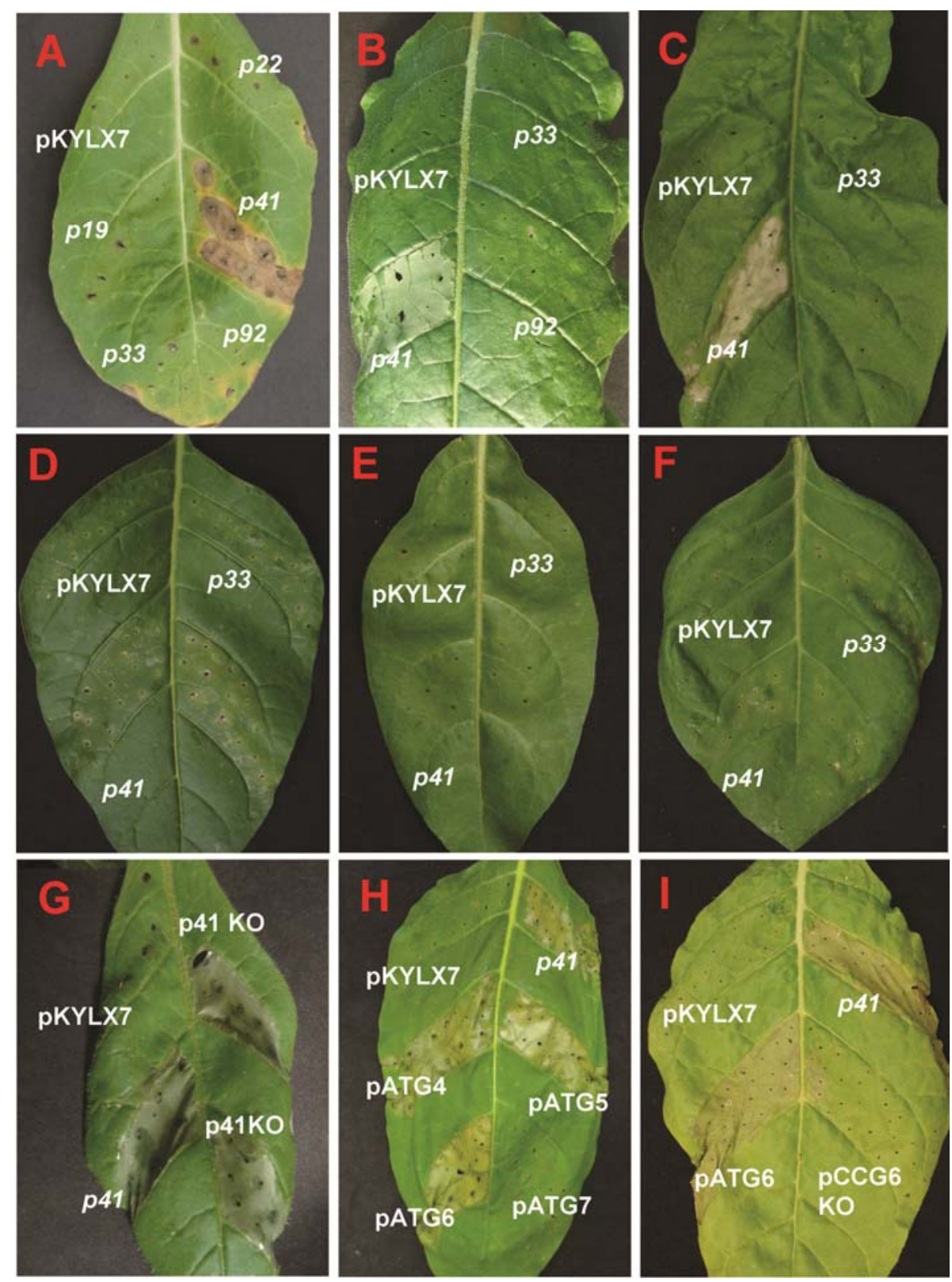

Fig. 2. Response of Nicotiana spp. to agroinfiltration of Tomato bushy stunt virus (TBSV) genes. A, Nicotiana longiflora, agroinfiltrated with TBSV genes, at 12 days after infiltration (dai). B, $N$. langsdorffii, agroinfiltrated with TBSV genes, at 2 dai. C, $N$. bonariensis, agroinfiltrated with TBSV genes, at 5 dai. D, $N$. rustica, agroinfiltrated with TBSV genes, at 5 dai. E, $N$. undulata, agroinfiltrated with TBSV genes, at 5 dai. F, $N$. arentsii, agroinfiltrated with TBSV genes, at 5 dai. G, $N$. langsdorffii, agroinfiltrated with $\mathrm{p} 41$ and $\mathrm{p} 41 \mathrm{KO}$, at 2 dai. $\mathbf{H}, N$. langsdorffii, agroinfiltrated with $p 41$ deletion constructs, at 3 dai. I, $N$. langsdorffii, agroinfiltrated with $p 41$ deletion constructs pATG6 and pCCG6 KO, at 3 dai. The pKYLX7 panel consists of the empty binary vector. 
Agroinfiltration of $\mathrm{p} 41 \mathrm{KO}$ into $N$. langsdorffii resulted in the development of an HR that could not be distinguished in appearance or timing from the wild-type $p 41$ (p41wt) construct (Fig. $2 \mathrm{G})$. To investigate whether the mutations introduced into $\mathrm{p} 41$ $\mathrm{KO}$ had abolished translation of the $\mathrm{P} 41$ protein, we infiltrated p41wt and p41KO constructs into $N$. benthamiana leaves and tested infiltrated tissue with an ELISA directed against TBSV virions and $\mathrm{P} 41$ protein. To increase the sensitivity of the transient expression assay, we co-agroinfiltrated the p41wt and p41KO constructs with a plasmid that expressed the TBSV P19 protein, a silencing suppressor that is commonly used to enhance and extend protein expression (Angel et al. 2011;

WT 5' ATG GCA ATG GTA AAG AGA AAC3' p41 KO 5'ATG GCA ATG GTA AAG TGA AAC3'

WT (cont.) 5' AAC AAC ACG GGA ATG ATC3' p41 KO (cont.) 5'AAC AAC ACG TGA TTC ATC3'

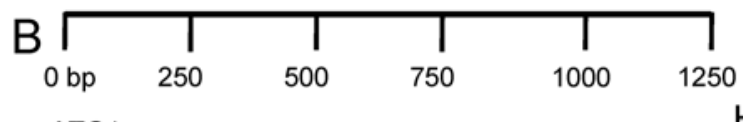

ATG1

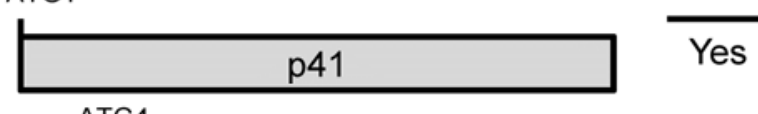

ATG4

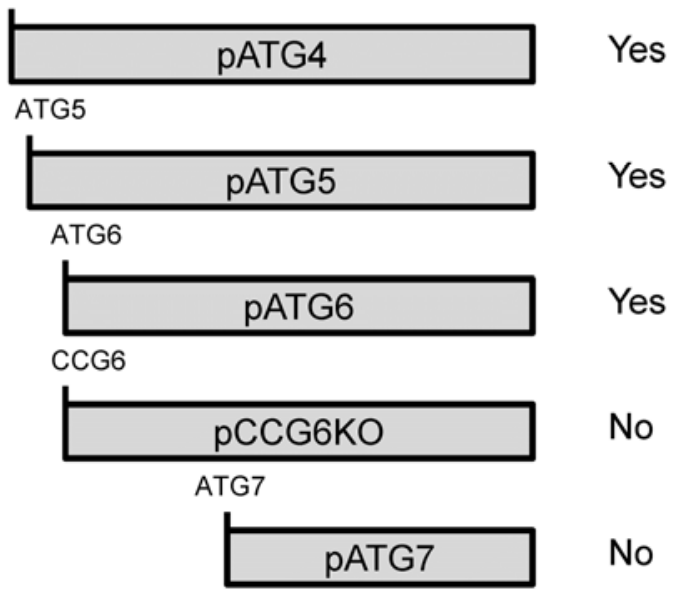

Fig. 3. Structure of mutated Tomato bushy stunt virus coat protein clones for agroinfiltration into Nicotiana spp. A, Start codons present in the first 13 codons of the wild type (WT) sequence are highlighted in bold. Coat protein codons targeted for mutation in $\mathrm{p} 41 \mathrm{KO}$ are highlighted in bold and underlined. B, Truncated coat proteins tested for hypersensitive response in Nicotiana spp. The number associated with each ATG indicates the position of that start codon in the coat protein sequence.
Scholthof 2006; Voinnet et al. 1999). Surprisingly, the expression level of $\mathrm{P} 41$ protein in tissue agroinfiltrated with $\mathrm{p} 41 \mathrm{KO}$ was indistinguishable from the level of $\mathrm{P} 41$ protein detected in tissue agroinfiltrated with the wild-type construct (p41wt) (Table 2 , test category 1 ), indicating that the mutations introduced into p41KO were not effective in blocking its translation. Two additional, independent ELISA tests confirmed that P41 epitopes were expressed from the construct $\mathrm{p} 41 \mathrm{KO}$ (data not shown).

A further inspection of the $p 41$ nucleotide sequence revealed additional start codons that could theoretically allow for initiation of translation and synthesis of a truncated coat protein sequence. Given the inconclusive results observed with $\mathrm{p} 41 \mathrm{KO}$, we created a series of mutants in which increasingly larger portions of the $5^{\prime}$ end of the $p 41$ gene were deleted (Fig. 3B). Each of these constructs was cloned into pKYLX7 and agroinfiltrated into leaf panels of $N$. langsdorffii along with $\mathrm{p} 41 \mathrm{wt}$ and pKYLX7 empty vector. Constructs pATG4, pATG5, and pATG6 consistently elicited HR, indicating that the first $79 \mathrm{co}-$ dons of $p 41$ were not necessary for HR elicitation (Figs. $2 \mathrm{H}$ and 3B). By contrast, the capacity of construct pATG7 to elicit HR was abolished. The pATG6 construct was also agroinfiltrated into $N$. benthamiana leaves by itself and co-agroinfiltrated with p19 to evaluate whether its expression could be confirmed. We found that a significant level of coat protein epitopes was present in the agroinfiltrated tissues when pATG6 was co-agroinfiltrated individually or co-agroinfiltrated with the TBSV p19 gene (Table 2, test categories 2 and 3).

To determine whether the truncated ATG6 protein or its nucleotide sequence was responsible for $\mathrm{HR}$, we mutated the start codon of construct pATG6 to CCG (construct pCCG6 $\mathrm{KO}$ ), and found that this construct was unable to elicit HR upon agroinfiltration into $N$. langsdorffii (Fig. 2I). Furthermore, the ELISA revealed that no coat protein epitopes could be detected in $N$. benthamiana leaf tissues (Table 2, test categories 2 and 3). Two additional, independent ELISA tests confirmed that P41 epitopes were expressed from the construct pATG6 and not from pCCG6KO. This study showed that the coat protein of TBSV, rather than the viral RNA, was responsible for eliciting HR in $N$. langsdorffii and $N$. longiflora. Furthermore, the first 79 amino acids of the P41 protein did not contribute to HR elicitation.

\section{The HR elicited by TBSV P41 protein is conserved among Nicotiana spp. within the Alatae section.}

We showed that three Nicotiana spp. belonging to the Alatae section ( $N$. langsdorffii, $N$. bonariensis, and $N$. longiflora) responded with HR to TBSV, CNV, and CymRSV virion inoculations, and that all three species responded to TBSV $p 41$ agroinfiltration with HR. Based on the results with these three species, we hypothesized that other members of the Alatae

Table 2. Detection of the Tomato bushy stunt virus (TBSV) coat protein and mutant coat protein sequences in Nicotiana benthamiana leaf panels by enzymelinked immunosorbent assay

\begin{tabular}{lccc}
\hline & \multicolumn{3}{c}{ Absorbance at 405 $\mathbf{~ n m}^{\mathbf{a}}$} \\
\cline { 2 - 4 } Treatment & Test category 1 (+P19) & Test category 2 (+P19) & Test category 3 (-P19) \\
\hline Healthy sap & $0.068 \pm 0.007$ & $0.025 \pm 0.011$ & $0.032 \pm 0.012^{\mathrm{b}}$ \\
pKYLX7 vector & $0.085 \pm 0.021$ & $0.024 \pm 0.006$ & $0.020 \pm 0.007$ \\
p41wt & $0.424 \pm 0.113$ & $0.436 \pm 0.019$ & $0.185 \pm 0.014$ \\
p41KO & $0.446 \pm 0.215$ & $\mathrm{nt}$ & $\mathrm{nt}$ \\
pATG6 & $\mathrm{nt}$ & $0.142 \pm 0.058$ & $0.053 \pm 0.015$ \\
pCCG6 KO & $1.700 \pm 0.068$ & $0.048 \pm 0.042$ & $0.011 \pm 0.008$ \\
TBSV-infected $^{c}$ & $1.113 \pm 0.055$ & $0.915 \pm 0.114$ \\
\hline
\end{tabular}

${ }^{a}$ Each test category was repeated in at least three independent tests. The results presented are of one test for each category. One-way analysis of variance was performed for three biological replications per treatment. Mean differences were calculated using Fisher's protected least significant difference; nt $=$ not included in this test.

${ }^{\mathrm{b}}$ Because of heterogeneous variances for this experiment, $\mathrm{a} \log _{10}$ transformation was required for variance stabilization.

${ }^{\mathrm{c}}$ Infected tissue in this sample originated from Tomato bushy stunt virus (TBSV) virion inoculation. 
section might respond to TBSV P41 with HR. The section Alatae of Nicotiana contains five additional species but only four were readily available from the Nicotiana collection at North Carolina State University. We obtained two accessions of $N$. alata, two accessions of $N$. forgetiana, two accessions of $N$. plumbaginifolia, and one accession of $N$. mutabilis. The fifth species, $N$. azambujae, is known only by ancient herbarium specimens from Brazil (Clarkson et al. 2004; Lim et al. 2006) and, therefore, could not be included in our test.

To determine whether the HR elicited by the TBSV P41 protein is conserved among the other four available species within section Alatae, we first evaluated the response of these species to TBSV virions and found that they all responded to TBSV infection with necrotic local lesions (Table 3; Supplementary Figure S8). Both of the accessions of $N$. alata, both accessions of $N$. forgetiana, and the single accession of $N$. mutabilis were scored as resistant, because no symptoms appeared on upper, noninoculated leaves, and an ELISA of those leaves could not detect any evidence of systemic spread of the virus (data not shown). By contrast, both of the accessions of $N$. plumbaginifolia were scored as susceptible, as evidenced by the symptoms that developed in the upper noninoculated leaves and the confirmation of virions in these leaves with an ELISA test (data not shown).

To evaluate which TBSV proteins might be responsible for eliciting HR in members of the Alatae section, we agroinfiltrated constructs that expressed the P41, P19, and P22 proteins as well as P33 and P92 into Nicotiana leaf panels, along with the empty vector pKYLX7. Both of the accessions of $N$. alata and $N$. forgetiana as well as the unique accession of $N$. mutabilis responded with HR to agroinfiltration of the TBSV $p 41$ gene (Table 3; Supplementary Figure S9A to D). N. bonariensis, tested in earlier experiments (Fig. 2C), was included as a positive control for elicitation of HR by P41. Interestingly, the $N$. forgetiana TW50 accession also responded to the TBSV P22 protein with HR but the $N$. forgetiana accession TW51 did not (Table 3). The TBSV P41 protein failed to elicit HR in both accessions of $N$. plumbaginifolia; instead, these two accessions responded with HR to the TBSV P19 protein after 10 dai (Table 3). This study showed that the HR-type resistance in the Alatae section is triggered primarily by TBSV P41, although a few members may also respond with HR to either P22 or P19.

\section{DISCUSSION}

In this study, we screened a total of 22 Nicotiana species belonging to 10 of 13 taxonomic sections of the genus (Fig. 4) (Clarkson et al. 2004) for resistance to the tombusviruses TBSV, $\mathrm{CNV}$, and CymRSV. Of 22 species, 18 were resistant, and resistance was manifested in at least two different forms. In all,
13 species responded with HR-type resistance, whereas another five were resistant but either had no visible response or responded with chlorotic lesions rather than necrotic lesions (Table 1; Fig. 4). Agroinfiltration can be used to identify avr determinants in plants that respond with HR; therefore, we evaluated the capacity of tombusvirus P22 and P19 proteins, previously identified as avr determinants, to trigger HR. Surprisingly, very little new information was revealed in the initial screen. The P22 protein triggered HR in N. glutinosa and N. edwardsonii, as previously described (Angel et al. 2011; Scholthof et al. 1995a), and the only other species that recognized P22 was one of the accessions of $N$. forgetiana. Similarly, the P19 protein triggered HR in N. sylvestris and N. tabacum, as previously described (Angel et al. 2011; Scholthof et al. 1995a), and the only other species that recognized P19 was $N$. bonariensis. Consequently, we considered that tombusvirus proteins in addition to P22 and P19 must act as avr determinants in some Nicotiana spp.

To identify new TBSV avr determinants, we used agroinfiltration for expression of the P41, P33, and P92 proteins of TBSV in Nicotiana spp. Of the three proteins, only P41 elicited HR, in $N$. langsdorffii, $N$. bonariensis, and $N$. longiflora. We next sought to determine whether the TBSV P41 protein or its RNA sequence was responsible for triggering $\mathrm{HR}$, and this turned out to be more difficult than we initially expected. A previous study conducted with the related tombusvirus CymRSV suggested that the $p 41$ RNA sequence, rather than the protein, was responsible for eliciting HR in the solanaceous host D. stramonium (Szittya and Burgyán 2001). The authors created a frameshift after the third start codon of the CymRSV $p 41$ gene which, theoretically, would alter the coat protein sequence after the 15 th amino acid, and the resultant protein would only be 61 amino acids in length. This frameshift mutant was able to trigger a rapid HR in $D$. stramonium. The authors concluded that the RNA encoding the CymRSV coat protein was the elicitor rather than the protein sequence. However, they did not check to see whether coat protein synthesis from their frameshift mutant was actually blocked in plants. Furthermore, Desvoyes and Scholthof (2002) showed that an infectious TBSV clone that lacked the capacity to produce a coat protein due to a small in-frame deletion was prone to recombination events in planta that restored the coat protein reading frame. Consequently, an infectious clone of a tombusvirus has the capacity for rapid coat protein RNA rearrangements. One benefit of an agroinfiltration assay is that it eliminates the possibility of intramolecular recombination associated with the replication of tombusviruses.

The TBSV $p 41$ gene has a cluster of start codons near the $5^{\prime}$ terminus (Fig. 3A), an arrangement similar to CymRSV. In our case, we introduced two stop codons after the second TBSV p41 start codon and we mutated the third start codon in an attempt to

Table 3. Response of Nicotiana spp. within the Alatae section to Tomato bushy stunt virus (TBSV) virions and agroinfiltration of tombusvirus genes

\begin{tabular}{|c|c|c|c|c|c|}
\hline \multirow[b]{2}{*}{ Nicotiana spp. } & \multirow[b]{2}{*}{ Section } & \multirow[b]{2}{*}{ TBSV virion inoculation ${ }^{b}$} & \multicolumn{3}{|c|}{ HR induced by agroinfiltration ${ }^{a}$} \\
\hline & & & $p 41$ & $p 22$ & p19 \\
\hline Nicotiana langsdorffii & Alatae & $\mathrm{HR}$ & $\mathrm{HR}$ & $\mathrm{nr}$ & $\mathrm{nr}$ \\
\hline N. alata TW7 & Alatae & HR & HR & $\mathrm{nr}$ & $\mathrm{nr}$ \\
\hline N. alata TW8 & Alatae & HR & HR & $\mathrm{nr}$ & $\mathrm{nr}$ \\
\hline N. forgetiana $\mathrm{TW} 50$ & Alatae & $\mathrm{HR}$ & $\mathrm{HR}$ & HR & $\mathrm{nr}$ \\
\hline N. forgetiana TW51 & Alatae & HR & HR & $\mathrm{nr}$ & $\mathrm{nr}$ \\
\hline N. mutabilis & Alatae & HR & HR & $\mathrm{nr}$ & $\mathrm{nr}$ \\
\hline N. bonariensis & Alatae & HR & HR & $\mathrm{nr}$ & HR \\
\hline N. longiflora & Alatae & HR & HR & $\mathrm{nr}$ & $\mathrm{nr}$ \\
\hline N. plumbaginifolia TW106 & Alatae & HR-SN & $\mathrm{nr}$ & $\mathrm{nr}$ & HR \\
\hline N. plumbaginifolia TW108 & Alatae & HR-SN & $\mathrm{nr}$ & $\mathrm{nr}$ & HR \\
\hline N. sylvestris & Sylvestres & HR & $\mathrm{nr}$ & $\mathrm{nr}$ & HR \\
\hline
\end{tabular}

${ }^{a}$ Hypersensitive response $(\mathrm{HR})=$ agroinfiltrated tissue turned necrotic and $\mathrm{nr}=$ no visible reaction upon agroinfiltration of construct.

${ }^{\mathrm{b}} \mathrm{HR}=$ necrotic local lesions, no development of systemic symptoms or detection of virions in upper, noninoculated leaves; and HR-SN = inoculated leaves develop HR but symptoms develop and virions detected in upper, noninoculated leaves. 
block translation of the $p 41$ gene. Similar to CymRSV, we found that our mutant construct triggered HR in an agroinfiltration assay in $N$. langsdorffii. However, our ELISA results unambiguously showed that TBSV coat protein epitopes were translated in spite of the introduction of stop codons, an indication that the TBSV P41 protein sequence might be responsible for HR induction rather than the RNA. A series of deletion constructs showed that the first 79 amino acids of P41 did not contribute to HR development. Finally, a mutation of start codon ATG6 to CCG in construct pCCG6 abolished HR development in N. langsdorffii and production of coat protein epitopes in $N$. benthamiana. We concluded that the TBSV coat protein, rather than the RNA, triggered HR in Nicotiana spp.

$N$. langsdorffii, $N$. bonariensis, and $N$. longiflora are all members of section Alatae of Nicotiana. Consequently, we investigated whether the other four species of this section might also recognize the TBSV P41 protein as an avirulence determinant. $N$. alata, $N$. mutabilis, and $N$. forgetiana responded with HR to virion inoculation, as well as agroinfiltration and expression of the TBSV P41 protein. The fourth species, $N$.

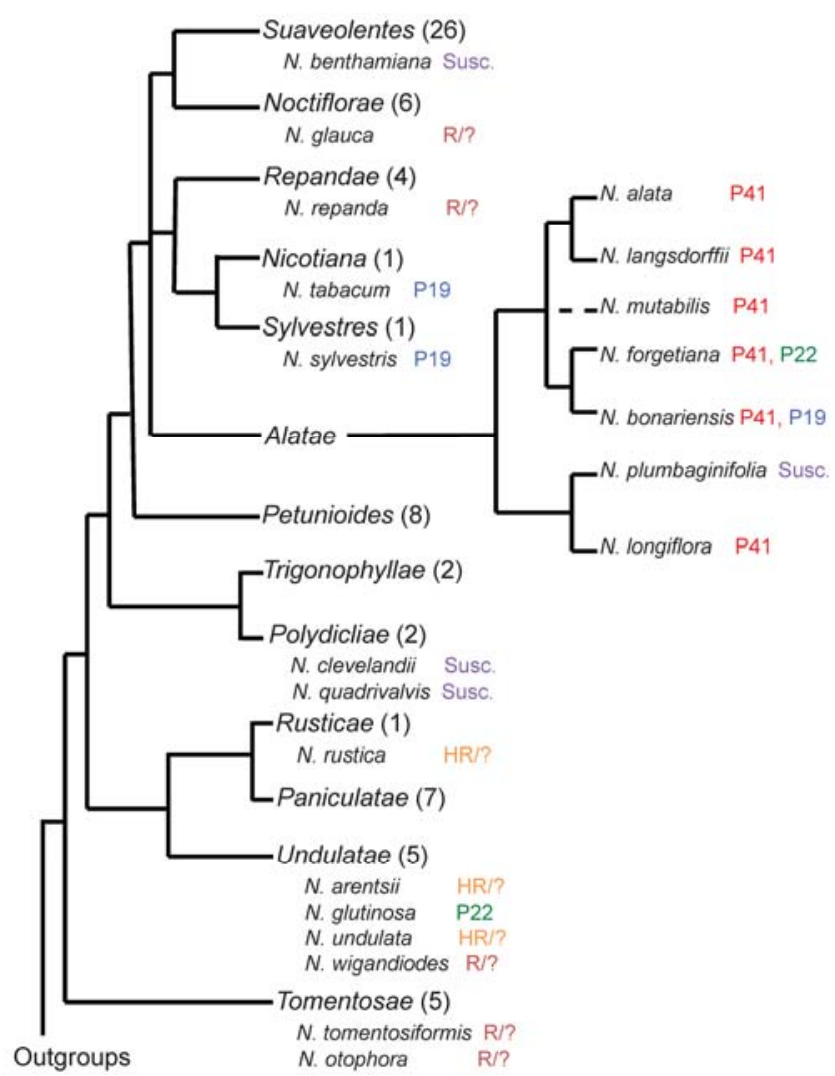

Fig. 4. Identification of Tomato bushy stunt virus avirulence determinants within the Nicotiana sections. The phylogenetic relationships of the Nicotiana sections are proposed by Clarkson and associates (2004), based on sequence analyses of the plastid DNA. The number in parentheses after the section lists the total number of species in that section, whereas the Nicotiana spp. included in the host range tests are listed below each of the sections. Nicotiana edwardsonii is not included in this figure because it is a species hybrid between N. glutinosa and N. clevelandii (Christie 1969). The phylogeny of Nicotiana spp. in the section Alatae is derived from Lim and associates (2006) and Lee and associates (2008). The suggested position of $N$. mutabilis within the section is indicated by a dotted line. The TBSV avirulence determinants identified or confirmed in this study are listed after the species. Nicotiana spp. that responded with non-necrotic resistance are designated with an "R/?", which also emphasizes that the viral trigger for resistance remains unknown. The three Nicotiana spp. that responded with hypersensitive response (HR) but for which the avirulence determinant was not identified are designated by "HR/?". Species susceptible to TBSV are indicated by the abbreviation "Susc.". plumbaginifolia, was susceptible to TBSV virion inoculation, with the development of a systemic necrosis symptom. Interestingly, our agroinfiltration assays indicated that the TBSV P19 protein might be responsible for the systemic necrosis symptom rather than $\mathrm{P} 41$, because $N$. plumbaginifolia responded to agroinfiltration of the $p 19$ gene with a delayed HR.

The members of the Nicotiana genus have been the subject of numerous phylogenetic studies (Clarkson et al. 2004; Kelly et al. 2010; Knapp et al. 2004; Lim et al. 2006), which provide an intriguing opportunity to compare the presence of tombusvirus $R$ genes in Nicotiana spp. with the phylogenetic relationships of Nicotiana spp. For example, our observation that the TBSV P41 protein triggers HR in several members of the Alatae section suggests that these species might share a common $\mathrm{R}$ protein that recognizes $\mathrm{P} 41$, either through a direct interaction or indirectly through a second host protein (i.e., the guard hypothesis) (Dangl and McDowell 2006; Van der Biezen and Jones 1998). It is interesting that all five self-incompatible species of Alatae that are grouped by a strongly supported clade with a haploid chromosome number of 9 (Fig. 4) (Lim et al. 2006; Lee et al. 2008) were resistant to virion inoculations and responded consistently with HR to agroinfiltration of P41. Alternatively, it is also possible that the TBSV P41 protein is targeted by divergent $\mathrm{R}$ proteins in Alatae species. However in the absence of the sequence of the putative $R$ genes, it is not possible to know which scenario is correct. Dardick and associates (1999) mutagenized the coat protein of TMV to show that maintenance of an $\alpha$ helical bundle was necessary for HR elicitation in tobacco, eggplant, and pepper; this indicated a functional relationship between the $\mathrm{R}$ proteins from these solanaceous hosts. A similar mutagenic approach could be used to characterize motifs and or specific amino acids in the TBSV coat protein necessary for HR elicitation in the Alatae section.

Although resistance to $\mathrm{P} 41$ predominated in the Alatae section, some species in this group also exhibited resistance to P19 or P22 (Fig. 4). For example, $N$. bonariensis responded to both TBSV P41 and P19 with HR, whereas N. plumbaginifolia appeared to contain a defective version of an $\mathrm{R}$ protein that, in some manner, recognizes P19. Furthermore, one accession of $N$. forgetiana carries an $\mathrm{R}$ protein that recognizes $\mathrm{P} 22$. As with $\mathrm{P} 41$ resistance, it is not possible to state whether resistance to P19 or P22 in multiple Nicotiana spp. is due to convergent or divergent evolution; however, phylogenetic studies within the genus Nicotiana do allow for the transfer of $\mathrm{R}$ proteins between species. For example, Kelly and associates (2010) found parental sequences of $N$. sylvestris in $N$. plumbaginifolia, $N$. longiflora, and $N$. mutabilis; this ancestral connection might explain the presence of an $\mathrm{R}$ protein that recognizes $\mathrm{P} 19$ in both Sylvestres and Alatae sections that was progressively lost during the Alatae evolution. There may also be a connection, albeit more tenuous, between P22 resistance in $N$. glutinosa (section Undulatae) and N. forgetiana (section Alatae). Clarkson and associates (2010) conducted an analysis of the evolution of the nuclear glutamine synthetase gene, and suggested that the subclade of Alatae with $n=10$ chromosomes ( $N$. plumbaginifolia and N. longiflora) is a sister with the Undulatae or Paniculatae sections. However, there are still conflicts on the origin and phylogenetic position of $N$. glutinosa within the Undulatae section. Furthermore, there is no additional information to support a relationship between Alatae and Undulatae species that would explain the presence of a putative $R$ gene against P22 in species of both Nicotiana sections.

In conclusion, of the 13 Nicotiana spp. that respond with $\mathrm{HR}$ to tombusviruses, multiple $\mathrm{R}$ proteins or alleles have evolved to condition resistance (Fig. 4). One category of $\mathrm{R}$ protein present in $N$ glutinosa, $N$. edwardsonii, and $N$. forgetiana recognized the tombusvirus $\mathrm{P} 22$ protein. A second cate- 
gory of R protein present in N. sylvestris, N. tabacum, and $N$. bonariensis, as well as a potentially defective variant in $N$. plumbaginifolia, is able to recognize the P19 protein. A third category of $\mathrm{R}$ protein recognizes TBSV P41, which is widely dispersed within the Alatae section. There still remain three Nicotiana spp.-N. undulata, $N$. arentsii, and N. rustica-that responded with HR to inoculation of tombusvirus virions but the $a v r$ gene has not yet been identified. It may be that, in these three species, HR is determined by a combination of viral proteins, or perhaps by the $\mathrm{pX}$ protein of TBSV. Alternatively, it may be that protein expression levels attained through agroinfiltration are not sufficient to trigger HR in these hosts. Further research will be necessary to determine how these three Nicotiana spp. are able to recognize and respond to tombusviruses with HR.

\section{MATERIALS AND METHODS}

\section{Viruses and plants.}

Nicotiana seed were obtained from the U.S. Tobacco Germplasm Collection at North Carolina State University (Lewis and Nicholson 2007) as follows: N. clevelandii (plant introduction [PI] 555491), N. glutinosa (PI 555507), N. tabacum cv. NC 95 (PI 552380), N. benthamiana (PI 555478), N. edwardsonii (PI 555704), N. sylvestris (PI 555569), N. tomentosiformis (PI 555572), N. otophora (PI 555542), N. repanda (PI 555552), N. glauca (PI 555504), N. rustica (PI 555554), N. arentsii (PI 555475), N. undulata (PI 555574), N. wigandioides (PI 302471), N. langsdorffii (PI 42337), N. quadrivalvis (Syn. N. bigelovii) (PI 555485), N. bonariensis (PI 555489), and N. longiflora (PI555531). Seed of the following Nicotiana spp. belonging to the Alatae section were provided by $\mathrm{T}$. Holtsford from the University of Missouri (Columbia): $N$. alata TW7 (PI 42334) and TW8 (PI 555474 ), N. forgetiana TW50 (PI 555501) and TW51 (PI 555502), N. plumbaginifolia TW106 (PI 555548) and TW108 (PI 302478), and N. mutabilis (011205-1). To break dormancy, seed were treated for $30 \mathrm{~min}$ with commercial bleach at $50 \%$ strength $(2.6 \% \mathrm{NaOCl}$ [ $\mathrm{vol} /$ vol]) (Burke 1957).

The tombusviruses TBSV, CNV, and CymRSV have all been previously cloned in infectious form (Grieco et al. 1989; Hearne et al. 1990; Rochon and Johnston 1991). Infectious, uncapped transcripts derived from the clones were made according to Scholthof and associates (1993) and inoculated to either $N$. clevelandii or $N$. benthamiana to increase inoculum, and infected tissue was frozen for further inoculations. For inoculation of test plants, leaves infected with tombusviruses were ground with a mortar and pestle at a dilution of approximately 1:20 (wt/vol) with inoculation buffer (0.05 M phosphate buffer, $\mathrm{pH} 7.0$ ), then gently rubbed onto Nicotiana leaves lightly dusted with 600-mesh Carborundum.

\section{ELISA tests for virion and P41 detection.}

To evaluate the capacity of tombusviruses to infect Nicotiana spp., DAS-ELISA (Clark and Adams 1977) was performed using primary antibodies and alkaline phosphatase conjugates purchased from Agdia (Elkhart, IN, U.S.A.) for TBSV and CymRSV, and from Acdia Inc. (Fayetteville, AR, U.S.A.) for CNV. Plant tissues were collected from upper, noninoculated leaves between 20 and $28 \mathrm{dpi}$, and samples were ground and loaded into polystyrene plates at a ratio of 1:10 tissue/grinding buffer $(1 \times$ phosphate buffered saline, $2 \%$ polyvinylpyrrolidone MW 40,000, and $0.2 \%$ bovine serum albumin). Colorimetric reactions with the substrate p-nitrophenyl phosphate were quantified at $405 \mathrm{~nm}$ using a Multiskan MCC/340 microplate reader (Thermo Fisher Scientific, Cincinnati, OH, U.S.A.). Comparable experiments to detect the TBSV P41 coat protein epitopes expressed through agroinfiltration were performed by DAS-ELISA at a ratio 1:5 or 1:10 tissue/grinding buffer, using primary antibodies and alkaline phosphatase conjugate purchased from Agdia for TBSV. All experiments were repeated three times, with three biological and two technical replicates per treatment. Absorbances at $405 \mathrm{~nm}$ were statistically analyzed by one-way analysis of variance, and mean differences were calculated using Fisher's protected least significant difference $(\alpha=0.05)$. Because of heterogeneous variances for the experiment using the pATG6 truncated protein and its knockout pCCG6 KO without P19, a $\log _{10}$ transformation was required for variance stabilization.

\section{Amplification and cloning of tombusvirus genes into the $A$. tumefaciens binary vector pKYLX7.}

The PCR amplification and cloning of the TBSV and CymRSV $p 22$ and $p 19$ genes and the CNV $p 21$ and $p 20$ genes into the A. tumefaciens binary vector pKYLX7 (Schardl et al. 1987), as well as their expression in Nicotiana spp., has been described previously (Angel et al. 2011). PCR primers were developed from the nucleotide sequence of the TBSV-cherry isolate (National Center for Biotechnology Information accession number M21958) to amplify and clone the TBSV p33, p92, and p41 genes. Primer sequences for PCR amplification were synthesized by Integrated DNA Technologies (Coralville, IA, U.S.A.). The template used for PCR of the $p 41$ gene, as well as the p41 mutant and deletion series, was the infectious clone TBSV-100 (Hearne et al. 1990) provided by H. Scholthof from Texas A\&M University (College Station). To clone the TBSV replicase genes $p 33$ and $p 92$, the template used for PCR was the clone $\mathrm{pMal} / \mathrm{TBSV} / \mathrm{p} 92$ provided by P. Nagy from the University of Kentucky (Lexington) (Rajendran and Nagy 2003), which was based on the mutant TBSV clone pHS-175 (Scholthof et al. 1995c). In the clone $\mathrm{pMal} / \mathrm{TBSV} / \mathrm{p} 92$, the $p 33$ ORF amber termination codon (UAG) has been replaced by a tyrosine codon such that the $p 92$ gene could also be amplified. All PCR primers are listed in Supplementary Table S1.

PCR conditions were one cycle at $95^{\circ} \mathrm{C}$ for $2 \mathrm{~min}$; followed by 35 cycles at $95^{\circ} \mathrm{C}$ for $1 \mathrm{~min}, 62^{\circ} \mathrm{C}$ for $1 \mathrm{~min}$, and $72^{\circ} \mathrm{C}$ for $1 \mathrm{~min}$; and finally one cycle at $72^{\circ} \mathrm{C}$ for $10 \mathrm{~min}$. The amplified DNA was subsequently purified by agarose gel elution using a QIAquick Gel Extraction kit (Qiagen Inc., Valencia, CA, U.S.A.) and cloned into the XhoI-SacI or XhoI-KpnI restriction enzyme sites of pGEM-7Zf(+) or into pGEM-T easy (Promega Corp., Madison, WI, U.S.A.). Nucleotide sequences of candidate clones were determined to confirm that the PCR reactions did not introduce errors. Sequencing of clones in both orientations was performed by the DNA Core Facility at the University of Missouri (Columbia). After confirming the fidelity of all sequences, the tombusvirus insert was subsequently cloned into the multiple cloning site of the A. tumefaciens binary vector pKYLX7 (Schardl et al. 1987) following standard cloning procedures (Sambrook et al. 1989). Escherichia coli transformants were selected on Luria-Bertani (LB) media containing kanamycin $(50 \mu \mathrm{g} / \mathrm{ml})$ and tetracycline $(12.5 \mu \mathrm{g} / \mathrm{ml})$ and tested by colony PCR and restriction enzyme digestions for the presence of the tombusvirus insert.

\section{Agroinfiltration.}

Clones of pKYLX7 containing the tombusvirus genes were mobilized by electroporation (PG200 Progenetor II; Hoefer Scientific Instruments, San Francisco) into A. tumefaciens AGL1 (Lazo et al. 1991). Transformants were selected on LB medium supplemented with kanamycin $(50 \mu \mathrm{g} / \mathrm{ml})$, tetracycline $(12.5 \mu \mathrm{g} / \mathrm{ml})$, and carbenicillin $(50 \mu \mathrm{g} / \mathrm{ml})$. The induction and infiltration medium was $20 \mathrm{mM}$ monohydrate 2-(N-morpholino) ethanesulfonic acid; $60 \mathrm{mM}$ sucrose; $55 \mathrm{mM}$ glucose, 
$\mathrm{pH} 5.4$; and $2 \mathrm{mM}$ acetosyringone dissolved into N-N-dimethylformamide. Agroinfiltrations were done when cell growth reached an optical density at $550 \mathrm{~nm}$ of 1.0 to 1.2 . The induced bacterial suspension was infiltrated on the abaxial surface of individual panels of fully expanded leaves of 6- to 10-weekold Nicotiana spp., using a needleless plastic syringe. Every experiment was repeated at least three times, four leaves per plant, two plants per replica.

\section{ACKNOWLEDGMENTS}

This research was partially funded by the Missouri Agricultural Experiment Station and the assistantship from D. F. Millikan Endowment Fund to C. A. Angel at the University of Missouri-Division of Plant Sciences. We thank P. Nagy for providing the clone pMal/TBSV/p92, T. Holtsford for scientific advice and seed of Nicotiana spp. section Alatae, the U.S. Tobacco Germplasm Collection at North Carolina State University, M. Ellersieck for statistical support, and S. Valdes for technical assistance.

\section{LITERATURE CITED}

Angel, C. A. Hsieh, Y.-C., and Schoelz, J. E. 2011. Comparative analysis of the capacity of tombusvirus P22 and P19 proteins to function as avirulence determinants in Nicotiana species. Mol. Plant-Microbe Interact. 24:91-99.

Burke, L.G. 1957. Overcoming seed dormancy in Nicotiana. Agron. J. 49:461.

Christie, S. R. 1969. Nicotiana hybrid developed as a host for plant viruses. Plant Dis. Rep. 53:939-941.

Clark, M. F., and Adams, N. A. 1977. Characteristics of the microplate method of enzyme-linked immunosorbent assay for the detection of plant viruses. J. Gen. Virol. 34:475-483.

Clarkson, J. J., Knapp, S., Garcia, V., Olmstead, R. G., Leitch, A. R., and Chase, M. W. 2004. Phylogenetic relationships in Nicotiana (Solanaceae) inferred from multiple plastid DNA regions. Mol. Phylogenet. Evol. 33:75-90.

Clarkson, J. J., Kelly, L. J., Leitch, A. R., Knapp, S., and Chase, M. W. 2010. Nuclear glutamine synthetase evolution in Nicotiana: Phylogenetics and the origins of allotetraploid and homoploid (diploid) hybrids. Mol. Phylogenet. Evol. 55:99-112.

Dangl, J. L., and McDowell, J. M. 2006. Two modes of pathogen recognition by plants. Proc. Natl. Acad. Sci. U.S.A. 103:8575-8576.

Dardick, C. D., Taraporewala, Z., Lu, B., and Culver, J. N. 1999. Comparison of tobamovirus coat protein structural features that affect elicitor activity in pepper, eggplant, and tobacco. Mol. Plant-Microbe Interact. $12: 247-251$

Desvoyes, B., and Scholthof, H. B. 2002. Host-dependent recombination of a Tomato bushy stunt virus coat protein mutant yields truncated capsid subunits that form virus-like complexes which benefit systemic spread. Virology 304:434-442.

Erickson, F., Holzberg, S., Calderon-Urrea, A., Handley, V., Axtell, M., Corr, C., and Baker, B. 1999. The helicase domain of the TMV replicase proteins induces the $\mathrm{N}$-mediated defense response in tobacco. Plant J. 18:67-75.

Goodin, M. M., Zaitlin, D., Naidu, R. A., and Lommel, S. A. 2008. Nicotiana benthamiana: Its history and future as a model for plant-pathogen interactions. Mol. Plant-Microbe Interact. 21:1015-1026.

Grieco, F., Burgyán, J., and Russo, M. 1989. The nucleotide sequence of Cymbidium ringspot virus RNA. Nucleic Acids Res. 17:6383.

Hearne, P. Q., Knorr, D. A., Hillman, B. I., and Morris, T. J. 1990. The complete genome structure and synthesis of infectious RNA from clones of Tomato bushy stunt virus. Virology 177:141-151.

Holmes, F. O. 1938. Inheritance of resistance to tobacco-mosaic disease in tobacco. Phytopathology 28:553-561.

Holmes, F. O. 1946. A comparison of the experimental host ranges of tobacco-etch and tobacco-mosaic viruses. Phytopathology 36:643-659.

Kelly, L. J., Leitch, A. R., Clarkson, J. J., Hunter, R. B., Knapp, S., and Chase, M. W. 2010. Intragenic recombination events and evidence for hybrid speciation in Nicotiana (Solanaceae). Mol. Biol. Evol. 27:781-799.

Knapp, S., Chase, M. W., and Clarkson, J. J. 2004. Nomenclatural changes and a new sectional classification in Nicotiana (Solanaceae). Taxon 53:73-82.

Knorr, D. A., and Dawson, W. O. 1988. A point mutation in the Tobacco mosaic virus capsid protein gene induces hypersensitivity in Nicotiana sylvestris. Proc. Natl. Acad. Sci. U.S.A. 85:170174.

Lazo, G. R., Stein, P. A., and Ludwig, R. A. 1991. A DNA transformation- competent Arabidopsis genomic library in Agrobacterium. BioTechnology 9:963-967.

Lee, C. B., Page, L. E., McClure, B. A., and Holtsford, T. P. 2008. Postpollination hybridization barriers in Nicotiana section Alatae. Sex Plant Reprod. 21:183-195.

Lewis, R. S., and Nicholson, J. S. 2007. Aspects of the evolution of Nicotiana tabacum L. and the status of the United States Nicotiana Germplasm Collection. Genet. Resour. Crop Evol. 54:727-740.

Lim, K. Y., Kovarik, A., Matyasek, R., Chase, M. W., Kapp, S., McCarthy, E., Clarkson, J. J., and Leitch, A. R. 2006. Comparative genomics and repetitive sequence divergence in the species of diploid Nicotiana section Alatae. Plant J. 48:907-919.

Meyers, B. C., Kozik, A., Griego, A., Kuang, H., and Michelmore, R. W. 2003. Genome-wide analysis of NBS-LRR-encoding genes in Arabidopsis. Plant Cell 15:809-834.

Nagy, P. D., and J. Pogany. 2008. Multiple roles of viral replication proteins in plant RNA virus replication. Methods Mol. Biol. 451:55-68

Padgett, H. S., and Beachy, R. N. 1993. Analysis of a tobacco mosaic virus strain capable of overcoming $\mathrm{N}$ gene-mediated resistance. Plant Cell 5:577-586.

Qu, F., and Morris, T. J. 2002. Efficient infection of Nicotiana benthamiana by Tomato bushy stunt virus is facilitated by the coat protein and maintained by p19 through suppression of gene silencing. Mol. PlantMicrobe Interact. 15:193-202.

Rajendran, K. S., and Nagy, P. 2003. Characterization of the RNA-binding domains in the replicase proteins of Tomato bushy stunt virus. J. Virol. 77:9244-9258.

Rochon, D. M., and Johnston, J. C. 1991. Infectious transcripts from cloned cucumber necrosis virus cDNA: Evidence for a bifunctional subgenomic mRNA. Virology 181:656-665.

Sambrook, J., Fritsch, E. F., and Maniatis, T. 1989. Molecular Cloning: A Laboratory Manual, 2nd ed. Cold Spring Harbor Laboratory Press, Cold Spring Harbor, NY, U.S.A.

Schardl, C. L., Byrd, A. D., Benzion, G., Altschuler, M. A., Hildebrand, D. F., and Hunt, A. G. 1987. Design and construction of a versatile system for the expression of foreign genes in plants. Gene 61:1-11.

Schoelz, J. E., Shepherd, R. J., and Daubert, S. 1986. Region VI of cauliflower mosaic virus encodes a host range determinant. Mol. Cell Biol. 6:2632-2637.

Schoelz, J. E., Wiggins, B. E., Wintermantel, W. M., and Ross, K. 2006 Introgression of a tombusvirus resistance locus from $N$. edwardsonii var. Columbia to $N$. clevelandii. Phytopathology 96:453-459.

Scholthof, H. B. 2006. The tombusvirus-encoded P19: From irrelevance to elegance. Nat. Rev. Microbiol. 4:405-411.

Scholthof, H. B., and Jackson, A. O. 1997. The enigma of pX: A hostdependent $c i s$-acting element with variable effects on tombusvirus RNA accumulation. Virology 237:56-65.

Scholthof, H. B., Morris, T. J., and Jackson, A. O. 1993. The capsid protein gene of Tomato bushy stunt virus is dispensable for systemic movement and can be replaced for localized expression of foreign genes. Mol. Plant-Microbe Interact. 6:309-322.

Scholthof, H. B., Scholthof K.-B. G., and Jackson A. O. 1995a. Identification of Tomato bushy stunt virus host-specific symptom determinants by expression of individual genes from a Potato virus $\mathrm{X}$ vector. Plant Cell 7:1157-1172.

Scholthof, H. B., Scholthof, K.-B. G., Kikkert, M., and Jackson, A. O. 1995b. Tomato bushy stunt virus spread is regulated by two nested genes that function in cell-to-cell movement and host-dependent systemic invasion. Virology 213:425-438.

Scholthof, K.-B. G., Scholthof, H. B., and Jackson A. O. 1995c. The tomato bushy stunt virus replicase proteins are coordinately expressed and membrane associated. Virology 208:365-369.

Szittya, G., and Burgyán, J. 2001. Cymbidium ringspot tombusvirus coat protein coding sequence acts as an avirulent RNA. J. Virol. 75:24112420.

Van der Biezen, E. A., and Jones, J. D. 1998. Plant disease-resistance proteins and the gene-for-gene concept. Trends Biochem. Sci. 23:454-456.

Voinnet, O., Pinto, Y. M., and Baulcombe, D. C. 1999. Suppression of gene silencing: A general strategy used by diverse DNA and RNA viruses. Proc. Natl. Acad. Sci. U.S.A. 96:14147-14152.

White, K. A., and Nagy, P. D. 2004. Advances in the molecular biology of tombusviruses: Gene expression, genome replication, and recombination. Prog. Nucleic Acid Res. Mol. Biol. 78:187-226.

Whitham, S., Dinesh-Kumar, S. P., Choi, D., Heyl, R., Corr, C., and Baker, B. 1994. The product of the tobacco mosaic virus resistance gene $N$ : Similarity to toll and the interleukin-1 receptor. Cell 78:1101-1115.

Yamamura, Y., and Scholthof, H. B. 2005. Tomato bushy stunt virus: A resilient model system to study virus-plant interactions. Mol. Plant Pathol. 6:491-502. 